\title{
Article \\ Characterization of the Chitinase Gene Family in Mulberry (Morus notabilis) and MnChi18 Involved in Resistance to Botrytis cinerea
}

\author{
Youchao Xin ${ }^{1,+}\left(\mathbb{D}\right.$, Donghao Wang ${ }^{1,+}$, Shengmei Han ${ }^{2}$, Suxia $\mathrm{Li}^{2}$, Na Gong ${ }^{1}$, Yiting Fan ${ }^{2}$ and Xianling Ji ${ }^{1, *}$ \\ 1 College of Forestry, Shandong Agricultural University, Tai'an 271018, China; ycxin@sdau.edu.cn (Y.X.); \\ wangdh1204@163.com (D.W.); gnsmooth@163.com (N.G.) \\ 2 State Key Laboratory of Crop Biology, Shandong Agricultural University, Tai'an 271018, China; \\ hanmei203203@163.com (S.H.); LI152153@163.com (S.L.); fan18303215087@163.com (Y.F.) \\ * Correspondence: xlji@sdau.edu.cn \\ + These authors contributed equally to this work.
}

Citation: Xin, Y.; Wang, D.; Han, S.; Li, S.; Gong, N.; Fan, Y.; Ji, X. Characterization of the Chitinase Gene Family in Mulberry (Morus notabilis) and MnChi18 Involved in Resistance to Botrytis cinerea. Genes 2022, 13, 98. https://doi.org/ 10.3390/genes 13010098

Academic Editor: Bing Yang

Received: 6 December 2021

Accepted: 30 December 2021

Published: 31 December 2021

Publisher's Note: MDPI stays neutral with regard to jurisdictional claims in published maps and institutional affiliations.

Copyright: (C) 2021 by the authors. Licensee MDPI, Basel, Switzerland. This article is an open access article distributed under the terms and conditions of the Creative Commons Attribution (CC BY) license (https:/ / creativecommons.org/licenses/by/ $4.0 /)$.

\begin{abstract}
Chitinase is a hydrolase that uses chitin as a substrate. It plays an important role in plant resistance to fungal pathogens by degrading chitin. Here, we conducted bioinformatics analysis and transcriptome data analysis of the mulberry (Morus notabilis) chitinase gene family to determine its role in the resistance to Botrytis cinerea. A total of 26 chitinase genes were identified, belonging to the GH18 and GH19 families. Among them, six chitinase genes were differentially expressed under the infection of B. cinerea. MnChi18, which significantly responded to B. cinerea, was heterologously expressed in Arabidopsis (Arabidopsis thaliana). The resistance of $\mathrm{MnChi18}$ transgenic Arabidopsis to B. cinerea was significantly enhanced, and after inoculation with B. cinerea, the activity of catalase (CAT) increased and the content of malondialdehyde (MDA) decreased. This shows that overexpression of MnChi18 can protect cells from damage. In addition, our study also indicated that MnChi18 may be involved in $B$. cinerea resistance through other resistance-related genes. This study provides an important basis for further understanding the function of mulberry chitinase.
\end{abstract}

Keywords: chitinase; B. cinerea; mulberry; $\mathrm{MnChi18}$

\section{Introduction}

Plants have several defense mechanisms to resist the invasion of pathogens, including pathogenesis-related (PR) proteins. Chitin is an insoluble polymer, $\beta$-1,4-linked N-acetyl-Dglucosamine. It is an important component of the cell wall of pathogenic fungi, but it does not exist in plants. Chitinase (EC 3.2.1.14), a subgroup of PR proteins [1], exists in a variety of organisms and catalyzes the hydrolysis of the $\beta$-1-4-linkage in the N-acetyl-D-glucosamine polymer of chitin. The resulting chitin fragments act as powerful pathogen-associated molecular patterns (PAMPs) that induce PAMP-triggered immunity [2,3]. Therefore, chitinase is considered to be a defense-related gene against pathogens containing chitin. Plant chitinases are divided into PR-3, PR-4, PR-8 and PR-11 [4]. Some studies have shown that the increase in chitinase levels is a response to pathogen attack [5-9]. Chitinases are either directly induced by pathogen elicitors or are constitutively expressed in the attacked tissue $[10,11]$. Chitinases isolated from plants can limit the growth of chitin-containing fungi in vitro [12,13] and in vivo [14], and the overexpressed chitinases in plants can resist infection by different fungal pathogens [15-19].

According to the similarity of amino acid sequence in the catalytic domain, chitinases can be divided into glycosyl hydrolases families 18 and 19 (GH18 and GH19). According to their phylogeny, catalytic reaction mechanism, three-dimensional (3D) structure and sensitivity to inhibitors, these families are further divided into five different classes (Classes I-V). GH18 chitinases (Classes III and V) are widely distributed in various organisms, while 
GH19 chitinases (Classes I, II and IV) mainly exist in plants and are the main source of chitinolytic activity [20].

Mulberry (Morus notabilis) is a typical perennial woody plant with very important economic and medicinal value, because mulberry contains abundant secondary metabolites beneficial to human health [21-24]. B. cinerea is a necrotizing fungal pathogen that can infect more than 200 plant species in the world, including important economic horticultural crops [25-27]. B. cinerea is also one of the main pathogens affecting mulberry [28]. So far, there are only a few reports of mulberry genes that are effective against $B$. cinerea $[28,29]$. Plant chitinases resist fungal infection by producing hypersensitivity reactions and inducing defense reactions. Therefore, chitinase is a good target for studying the defense response to B. cinerea. However, so far, the role of mulberry chitinase genes in resistance has not been systematically studied.

The availability of the mulberry genome and transcriptome data in response to $B$. cinerea infection has facilitated the identification of genome-wide chitinase gene families and the study of their resistance to $B$. cinerea infection $[29,30]$. This study reports the genome-wide identification and analysis of the mulberry chitinase gene family. The resistance of the chitinase gene to B. cinerea infection was studied. In addition, MnChi18 was heterologous expressed in Arabidopsis to study its function. Diverse approaches were used to study the resistance of transgenic Arabidopsis to B. cinerea, confirming that the $\mathrm{MnChi18}$ gene is involved in the defense mechanism of transgenic plants. These findings may provide effective genetic resources for improving mulberry resistance to $B$. cinerea.

\section{Materials and Methods}

\subsection{Identification of Chitinase Genes in Mulberry}

In order to identify the mulberry chitinase genes, genome sequence and annotation data were obtained from the Morus notabilis genome project [30]. The Hidden Markov Model (HMM) seed profiles of Glyco_hydro_18 (PF00704) and Glyco_hydro_19 (PF00182) from the Pfam database were downloaded [31]. HMMER3 (v.3.0) software was used to identify the mulberry chitinase gene [32]. Then, the presence of conserved domains of Glyco_hydro_18 or Glyco_hydro_19 was manually performed on all predicted chitinase genes.

\subsection{Phylogenetic Tree of Chitinase Genes}

To study the evolutionary relationship, ClustalW was used to align the full-length amino acid sequence of the chitinase protein under default settings, and we used MEGA6 to construct a neighbor-joining (NJ) phylogenetic tree [33]. Bootstrap analysis was performed with 1000 replicates.

\subsection{Quantitative Real-Time PCR}

Total RNA was isolated from the samples with TRIzol reagent (Invitrogen, Carlsbad, CA, USA). The QuantiNova ${ }^{\mathrm{TM}}$ SYBR Green PCR kit (Qiagen, Hilden, Germany) and StepOnePlus ${ }^{\text {TM }}$ Real-time PCR system (Applied Biosystems, Waltham, MA, USA) were used for qRT-PCR detection. AtActin and MnActin genes were used as internal control genes in Arabidopsis and mulberry, respectively. The qRT-PCR test performed three biological replicates. Details of the qRT-PCR primers are shown in Table S1.

\subsection{Plasmid Construction and Plant Transformation}

Under the control of the CaMV35S promoter, full-length coding sequences of MnChi18 (GenBank accession number: EXB55192.1) were cloned into the KpnI (5'-GGGTACCATGGCC TCTCCCAATCCAA-3') and SalI (5'-GCGTCGACTTAGCAAGTGAGATTGGATCCA-3') restriction sites of the pLGNL vector. Afterwards, the CaMV35S::MnChi18 recombinant plasmid was obtained. The recombinant pLGNL expression vector was transformed into Agrobacterium tumefaciens strain GV3101. MnChi18 was finally transferred into Arabidopsis (Columbia-0) by the floral dip method [34]. The homozygous lines of the $\mathrm{T}_{3}$ generation were studied. 


\subsection{Resistance Analysis of Transgenic Arabidopsis to B. cinerea}

The resistance test was used to detect the ability of transgenic Arabidopsis plants to resist $B$. cinerea. Transgenic seeds were germinated on 1/2 Murashige and Skoog (MS) agar medium. Seven-day-old seedlings were transferred to pots of nutrient soil and grown at $24{ }^{\circ} \mathrm{C} / 22{ }^{\circ} \mathrm{C}$ under a 16-h light/8-h dark photoperiod. The hyphal fragments were placed on the leaves of 21-day-old plants. The inoculated Arabidopsis plants were observed every 12 hours and photographed 36 hours later. The transgenic Arabidopsis plants with pLGNL were used as a control. The content of malondialdehyde (MDA) and the activity of catalase (CAT) were determined with a Malondialdehyde Assay Kit (Solarbio, Beijing, China) and Catalase Assay Kit (Solarbio, Beijing, China) according to the manufacturer's instructions. All treatments were repeated three times.

The contents of superoxide radical $\left(\mathrm{O}_{2}{ }^{-}\right)$and hydrogen peroxide $\left(\mathrm{H}_{2} \mathrm{O}_{2}\right)$ in leaves were determined by histochemical staining. The leaves were inserted into $0.1 \%$ nitroblue tetrazole (NBT) containing a $50 \mathrm{mM}$ potassium phosphate buffer $(\mathrm{pH} 7.8)$ for $\mathrm{O}_{2}{ }^{-}$detection [35]. For the detection of $\mathrm{H}_{2} \mathrm{O}_{2}$, a 3,3'-diaminobenzidine (DAB) solution was used in agro-infiltrated leaves [36]. The samples were placed in a $1.0 \mathrm{mg} / \mathrm{mL}$ DAB-HCl solution, darkly covered for $12 \mathrm{~h}$ at room temperature, and then placed in $95 \%$ ethanol for 5 minutes until brown spots of $\mathrm{H}_{2} \mathrm{O}_{2}$ and blue $\mathrm{O}_{2}{ }^{-}$precipitate appeared on the leaves.

\subsection{Statistical Analyses}

All data were calculated using SPSS 26.0 statistical software (SPSS Inc., Chicago, IL, USA) and Excel 2013 (Microsoft, Redmond, CA, USA). The results are expressed as the mean \pm standard error. Significant differences $(P<0.05)$ were measured by Student's t-test analysis.

\section{Results}

\subsection{Genome-Wide Identification and Phylogenetic Analysis of Chitinase Genes in Mulberry}

A total of 26 chitinase genes were identified from the mulberry genome sequence, among which 15 belonged to the GH18 subfamily (7 Class III and 8 Class V) and 11 belonged to the GH19 subfamily (3 Class I, 4 Class II and 4 Class IV) (Table 1). The 26 predicted chitinase proteins ranged in length from 104 (MnChi15) to 881 amino acids (aa) (MnChi23). The relative molecular mass ranged from $11.78 \mathrm{kDa}(\mathrm{MnChi15)}$ to $96.77 \mathrm{kDa}(\mathrm{MnChi23})$. The theoretical isoelectric points (pI) ranged from 4.56 (MnChi16) to 8.77 (MnChi19).

Table 1. Characterization of the chitinases in M. notabilis.

\begin{tabular}{|c|c|c|c|c|c|c|c|c|}
\hline Gene Name & Gene ID & Class & Domains & GenBank Acc. & CDS (bp) & Size (aa) & MW (kDa) & Predicted pI \\
\hline MnChi1 & L484_014360 & I & GH19 & EXB95387.1 & 978 & 325 & 34.73 & 7.80 \\
\hline MnChi2 & L484_014362 & I & GH19 & EXB95389.1 & 978 & 325 & 34.89 & 7.38 \\
\hline MnChi3 & L484_013887 & I & GH19 & EXB44469.1 & 762 & 253 & 27.84 & 6.42 \\
\hline MnChi4 & L484_007737 & II & GH19 & EXB55741.1 & 960 & 319 & 35.25 & 6.78 \\
\hline $\mathrm{MnChi5}$ & L484_012010 & II & GH19 & EXB97442.1 & 957 & 318 & 35.10 & 6.97 \\
\hline MnChi6 & L484_014359 & II & GH19 & EXB95386.1 & 627 & 208 & 21.98 & 6.30 \\
\hline MnChi7 & L484_026587 & II & GH19 & EXC35265.1 & 1032 & 343 & 37.92 & 6.44 \\
\hline MnChi8 & L484_022481 & III & GH18 & EXB52704.1 & 900 & 299 & 32.10 & 6.50 \\
\hline MnChi9 & L484_022482 & III & GH18 & EXB52705.1 & 897 & 298 & 32.01 & 5.36 \\
\hline MnChi10 & L484_020224 & III & GH18 & EXB97674.1 & 1527 & 508 & 54.85 & 5.26 \\
\hline MnChi11 & L484_011484 & III & GH18 & EXB72482.1 & 630 & 209 & 22.97 & 6.55 \\
\hline MnChi12 & L484_011486 & III & GH18 & EXB72483.1 & 903 & 300 & 32.71 & 8.65 \\
\hline MnChi13 & L484_000037 & III & GH18 & EXC45568.1 & 600 & 199 & 22.08 & 7.66 \\
\hline MnChi14 & L484_000761 & III & GH18 & EXC37464.1 & 2448 & 815 & 91.33 & 7.95 \\
\hline MnChi15 & L484_022490 & IV & GH19 & EXB52713.1 & 315 & 104 & 11.78 & 7.88 \\
\hline MnChi16 & L484_018124 & IV & GH19 & EXB55197.1 & 840 & 279 & 30.33 & 4.56 \\
\hline MnChi17 & L484_018118 & IV & GH19 & EXB55191.1 & 825 & 274 & 29.53 & 4.59 \\
\hline MnChi18 & L484_018119 & IV & GH19 & EXB55192.1 & 825 & 274 & 29.42 & 4.71 \\
\hline MnChi19 & L484_003149 & $\mathrm{V}$ & GH18 & EXC13800.1 & 1269 & 422 & 46.72 & 8.77 \\
\hline
\end{tabular}


Table 1. Cont.

\begin{tabular}{ccccccccc}
\hline Gene Name & Gene ID & Class & Domains & GenBank Acc. & CDS (bp) & Size (aa) & MW (kDa) & Predicted pI \\
\hline MnChi20 & L484_022978 & V & GH18 & EXB94872.1 & 1101 & 366 & 40.55 & 5.11 \\
MnChi21 & L484_001056 & V & GH18 & EXB47196.1 & 2121 & 706 & 79.36 & 8.10 \\
MnChi22 & L484_003690 & V & GH18 & EXC19668.1 & 2304 & 767 & 87.03 & 8.40 \\
$M n$ Chi23 & L484_017594 & V & GH18 & EXB62207.1 & 2646 & 881 & 96.77 & 6.56 \\
MnChi24 & L484_007185 & V & GH18 & EXB53242.1 & 936 & 311 & 34.89 & 6.35 \\
$M n$ Chi25 & L484_007186 & V & GH18 & EXB53243.1 & 909 & 302 & 33.99 & 7.79 \\
$M n$ Chi26 & L484_020088 & V & GH18 & EXB80831.1 & 822 & 273 & 30.56 & 5.96 \\
\hline
\end{tabular}

The phylogenetic analysis of the 31 chitinase sequences was carried out using the neighbor-joining method (Figure 1), and five types of chitinase proteins were identified, which was consistent with the previous Ammopiptanthus nanus chitinases [37]. The mulberry chitinase genes were divided into two large branches: one was composed of Classes I, II and IV, and the other was composed of Classes III and V.

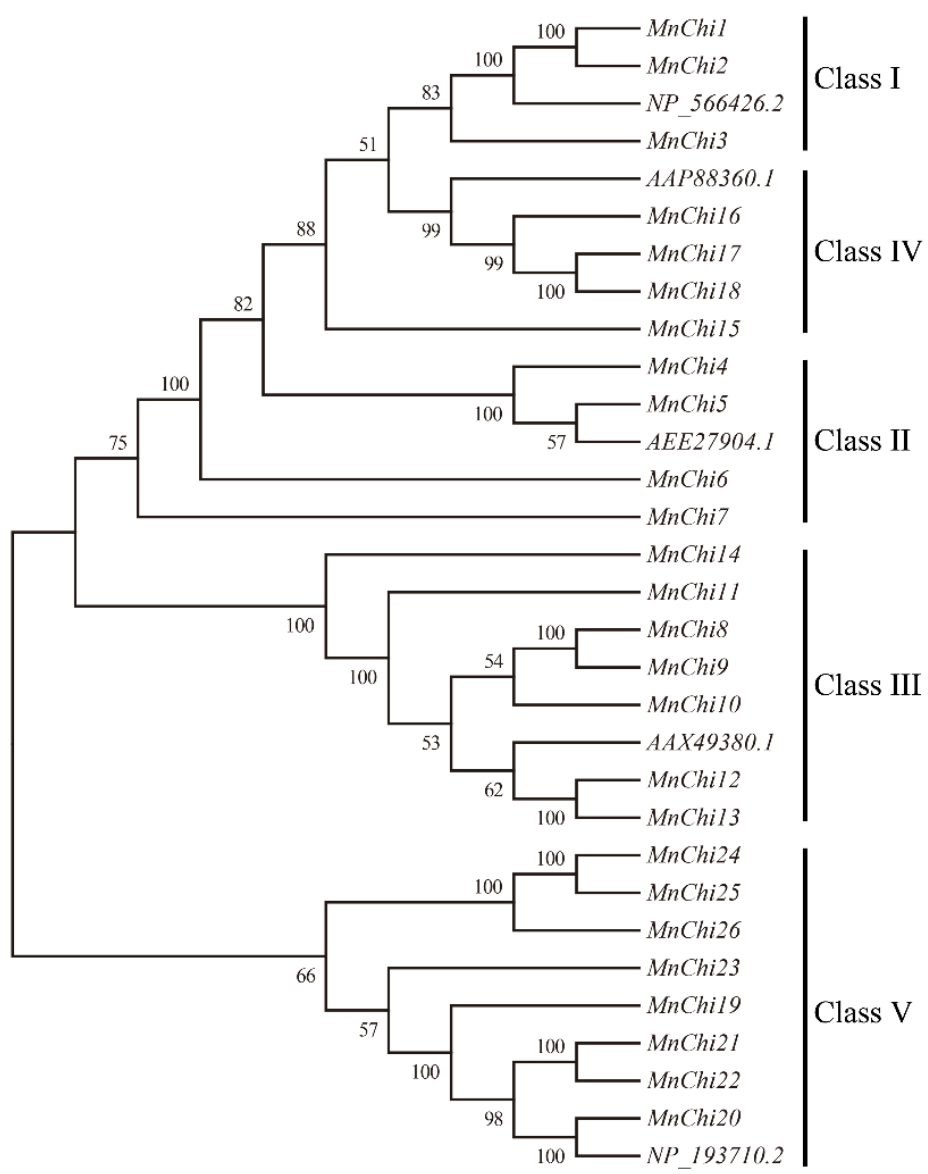

Figure 1. Phylogenetic tree of the chitinase genes from M. notabilis and Arabidopsis. The neighborjoining (NJ) was used to construct a phylogenetic tree. The tree was generated by chitinase amino acid sequences using MEGA6. The numbers represent confidence percentages.

\subsection{Expression Pattern of Mulberry Chitinases under the Infection of B. cinerea}

To study the resistance of mulberry chitinase genes to $B$. cinerea, we analyzed the expression pattern of chitinases based on our previous transcriptome data of mock-treated (Mock) and B. cinerea-inoculated (Inoculated) M. notabilis leaves [29]. With FPKM > 1.0, a total of $14 \mathrm{MnChis}$ were found to be expressed (Figure 2 and Table S2). With I Fold Change (Inoculated/Mock) $\mid>2$, the expression of four chitinases (MnChi3/14/17/18) in mulberry leaves was significantly upregulated after $B$. cinerea infection, and the expression of two 
chitinases (MnChi20/23) was significantly downregulated. These highly expressed chitinase genes suggested that they may be involved in mulberry resistance to B. cinerea. MnChi14 and $\mathrm{MnChi18}$ were the two genes with the most increased expression after infection of $B$. cinerea, and they may play an important role in resistance to $B$. cinerea infection. Then, the two genes were verified by qRT-PCR, and the results were consistent with the transcriptome data (Figure 3).

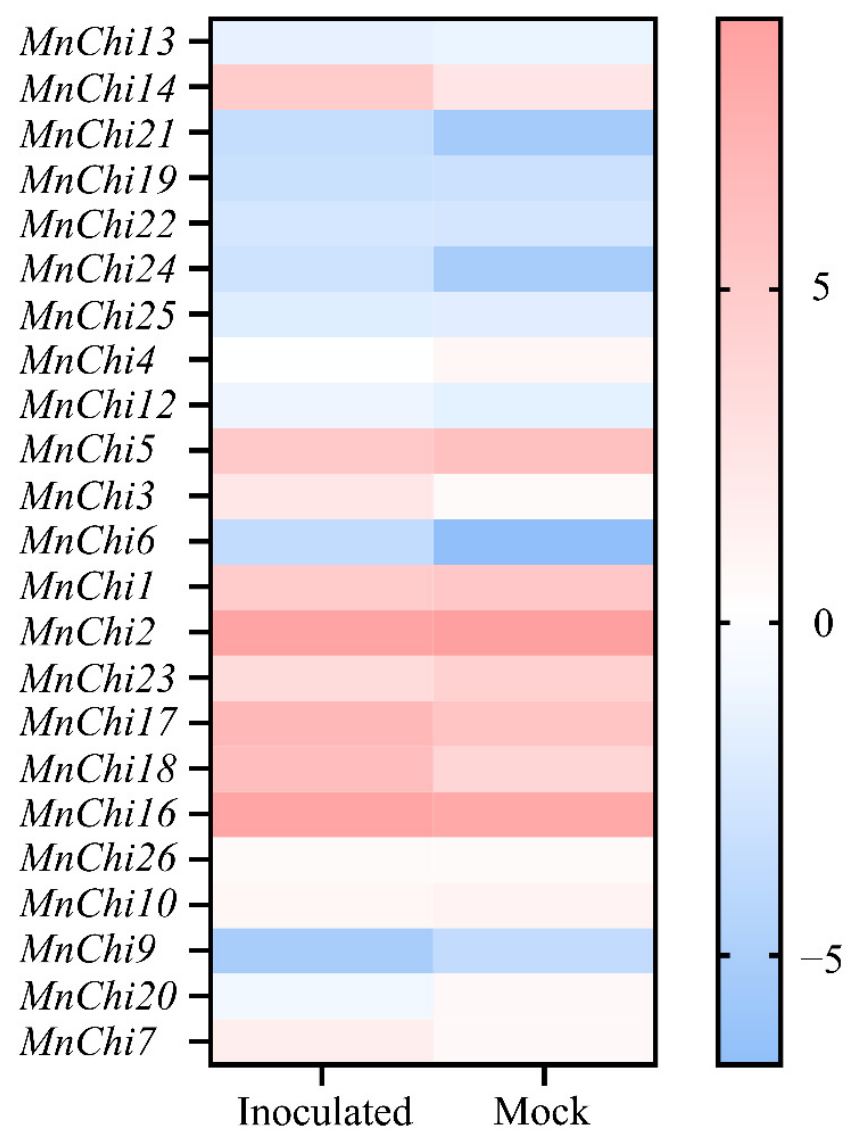

Figure 2. Heat map representation of the chitinase gene expression in mock-treated (Mock) and B. cinerea-inoculated (Inoculated) M. notabilis leaves. Log2 (RPKM) was used to convert the expression data to calculate the gene expression levels. The difference in gene expression was indicated by the color on the scale.
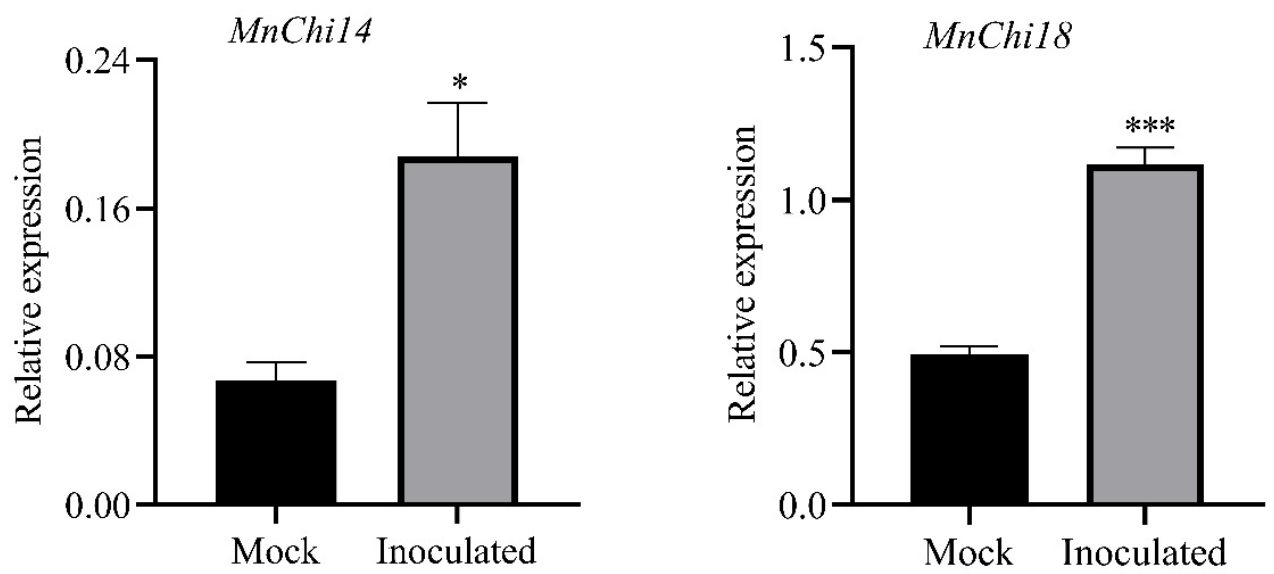

Figure 3. Relative expression of MnChi14 and MnChi18 in mock-treated (Mock) and B. cinereainoculated (Inoculated) M. notabilis leaves. Error bars indicate the standard deviation, $n=3$ ${ }^{*} p$-value $<0.05,{ }^{* * *} p$-value $<0.001$; two-tailed $t$-test $)$. 


\subsection{Ectopic Expression of MnChi18 in Arabidopsis Enhances Resistance to B. cinerea}

Under the control of Cauliflower mosaic virus (CaMV) 35S promoter, Arabidopsis plants were transformed with $M n C h i 18 \mathrm{cDNA}$, and several $\mathrm{T}_{3}$ transgenic lines were obtained. The $M n C h i 18$ gene expression was confirmed by analysis of transgenic Arabidopsis plants (Figure 4A). Three lines with significantly higher expression than the empty vector control were selected for follow-up study. To investigate the resistance of transgenic Arabidopsis with the $M n C h i 18$ gene to $B$. cinerea, the leaves of the transgenic Arabidopsis with an empty vector and $\mathrm{MnChi18}$ were inoculated with an agar block containing $B$. cinerea hyphae (Figure 4B). Compared with the empty vector control leaves that showed severe disease symptoms 36 hours after inoculation, all the leaves of the $M n C h i 18$ overexpressed lines showed only slight lesions. Quantitative analysis showed that transgenic Arabidopsis with $M n C h i 18$ gene inhibited the growth of $B$. cinerea compared with transgenic Arabidopsis with the empty vector (Figure $4 \mathrm{C}$ ). In addition, the production of reactive oxygen species (ROS) is the response of plants to stress. The DAB and NBT staining methods were used to detect the hydrogen peroxide $\left(\mathrm{H}_{2} \mathrm{O}_{2}\right)$ and superoxide $\left(\mathrm{O}_{2}{ }^{-}\right)$in leaves, respectively. In terms of phenotype, Arabidopsis transferred with empty vector showed large patches of dark brown after DAB staining, an indication of $\mathrm{H}_{2} \mathrm{O}_{2}$ accumulation, and large patches of dark blue after NBT staining, a marker for $\mathrm{O}_{2}{ }^{-}$, compared with the MnChi18 transgenic Arabidopsis (Figure 4D).

A

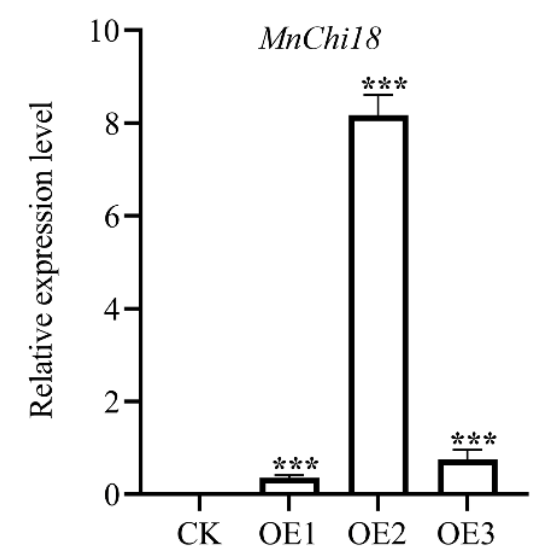

C

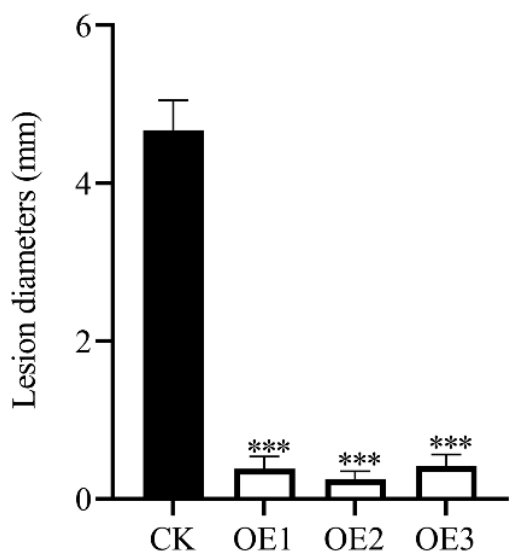

B

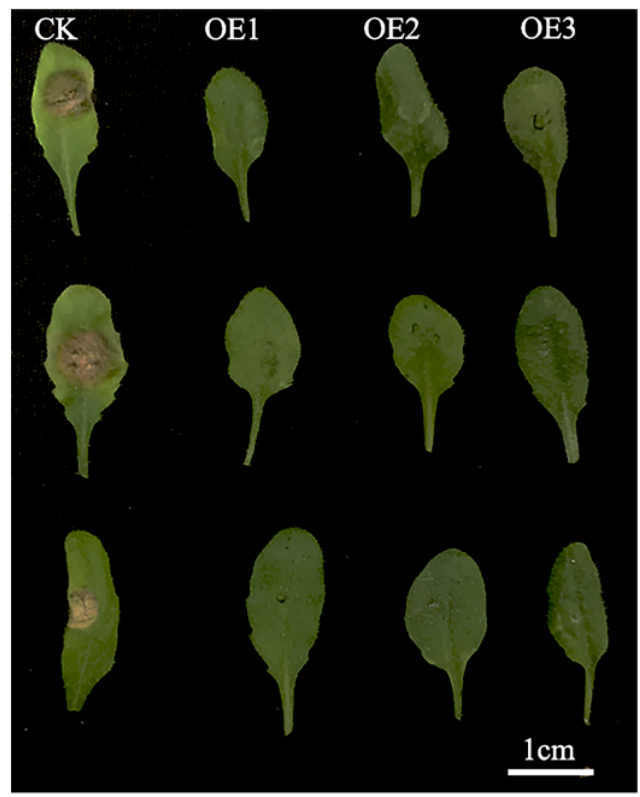

D

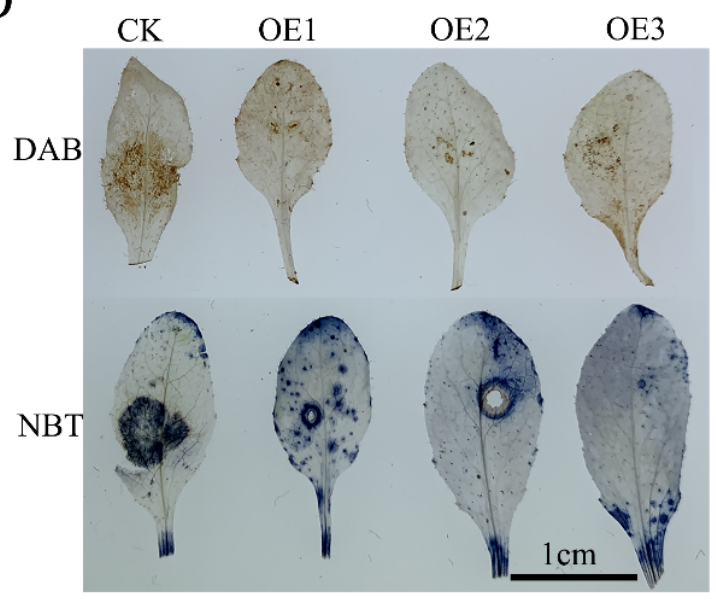

Figure 4. Resistance of transgenic Arabidopsis to B. cinerea. (A) Relative expression level of MnChi18 
in transgenic Arabidopsis leaves. (B) The leaves of Arabidopsis were photographed for 36 hours after being infected by $B$. cinerea. (C) Quantitative analysis of resistance of the empty vector transgenic (CK) and MnChi18 transgenic (OE) lines infected by B. cinerea. (D) DAB and NBT staining revealed $\mathrm{H}_{2} \mathrm{O}_{2}$ and $\mathrm{O}_{2}{ }^{-}$enrichment, respectively. Values are the average of three replicates. Error bars indicate SDs; ${ }^{* * *} p$-value $<0.001$.

\subsection{Detection of Biochemical Indices}

In order to verify the physiological changes of transgenic Arabidopsis with MnChi18 and the empty vector, the MDA content and CAT activity were determined (Figure 5). Before $B$. cinerea infection, there was no significant difference in the MDA content of transgenic Arabidopsis with $M n C h i 18$ and the empty vector. After $36 \mathrm{~h}$ of $B$. cinerea infection, the content of MDA in both $\mathrm{MnChi18}$ and empty vector transgenic plants increased, while the content of MDA in empty vector transgenic plants was significantly higher than that in $M n C h i 18$ transgenic plants (Figure 5A). These results suggested that plasma membrane damage was more serious in the empty vector transgenic plants than in the MnChi18 transgenic plants. Similarly, there was no significant difference in the CAT activity of transgenic Arabidopsis with $\mathrm{MnChi18}$ and the empty vector before the infection of $B$. cinerea. After $36 \mathrm{~h}$ of $B$. cinerea infection, the CAT activity of both $\mathrm{MnChi18}$ and the empty vector transgenic plants increased, and the CAT activity of the MnChi18 transgenic plants was significantly higher than that of the empty vector transgenic plants (Figure 5B). These results suggested that the $M n C h i 18$ transgenic plants are more resistant to oxidative damage.

A
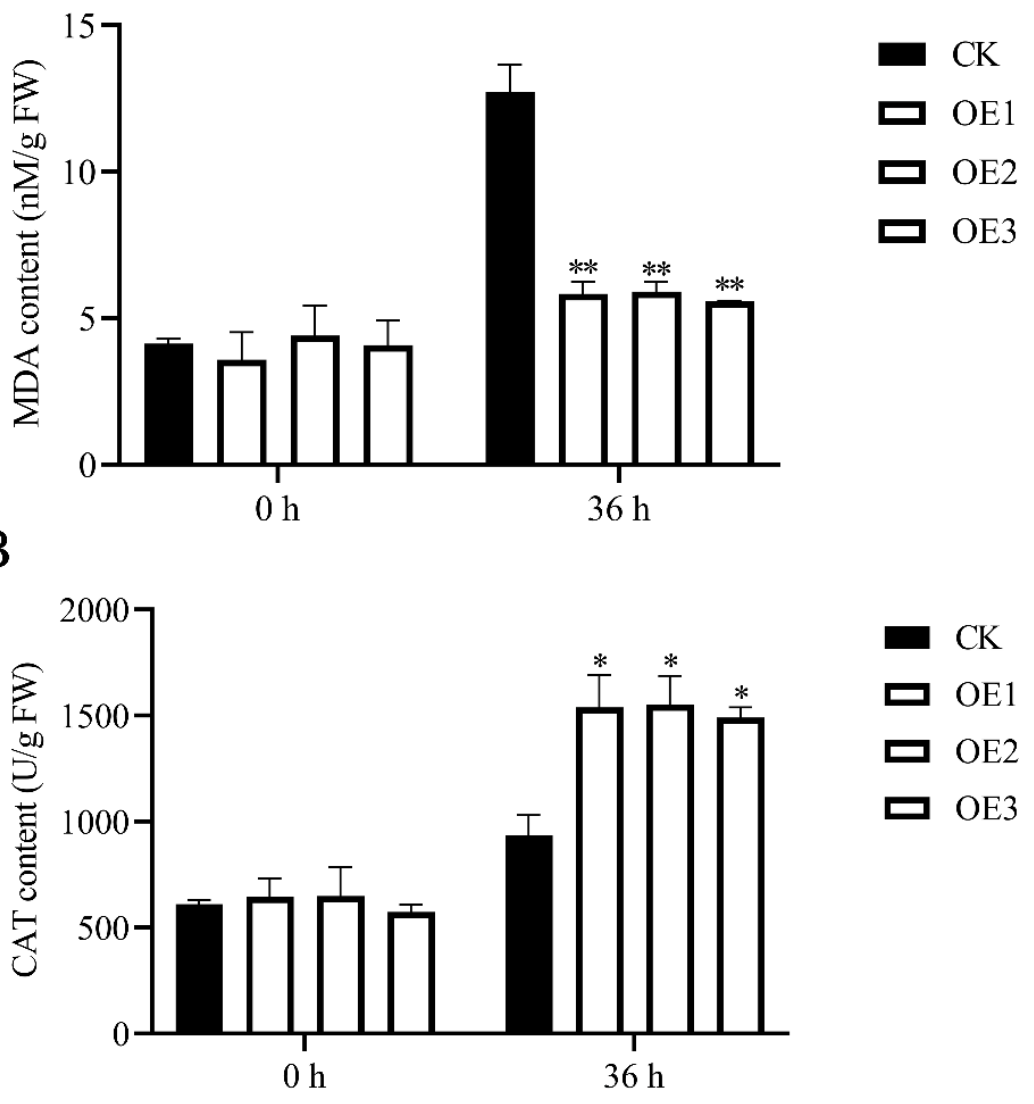

Figure 5. Determination of physicochemical indexes in B. cinerea-inoculated. (A) Malondialdehyde (MDA) content. (B) Catalase (CAT) activity. CK, empty vector transgenic plant; OE, MnChi18 transgenic plant. Values are the average of three replicates. Error bars indicate the standard deviation; ${ }^{*} p$-value $<0.05$ and ${ }^{* *} p$-value $<0.01$. 


\subsection{The Enhanced Expressions of Resistance-Related Genes in MnChi18 Transgenic Plants}

$P R 1, W R K Y 33, \beta-1,3$-glucanase 2 (BG2) and hypersensitive induced reaction 1 (HIR1) are the defense-associated marker genes of a plant. The results showed that there was no significant difference between AtPR1 and AtWRKY33 in transgenic Arabidopsis with $\mathrm{MnChi18}$ and the empty vector before and after B. cinerea infection (Figure S1). AtBG2 and AtHIR1 had no significant difference in transgenic Arabidopsis with MnChi18 and the empty vector before the infection of $B$. cinerea. However, the expression levels of $A t B G 2$ and AtHIR1 were upregulated in both MnChi18 and the empty vector transgenic plants after $36 \mathrm{~h}$ of $B$. cinerea infection, and the $M n C h i 18$ transgenic plants were significantly higher than the empty vector transgenic plants (Figure 6). These results indicated that when the $\mathrm{MnChi18}$ gene was introduced into Arabidopsis, it could resist the infection of $B$. cinerea by inducing the expression of resistance-related genes.

A

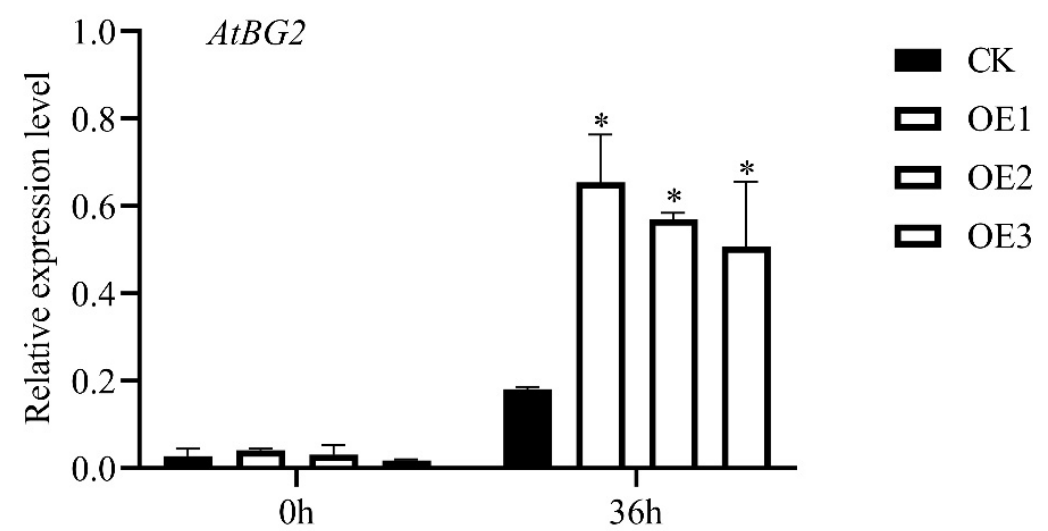

B

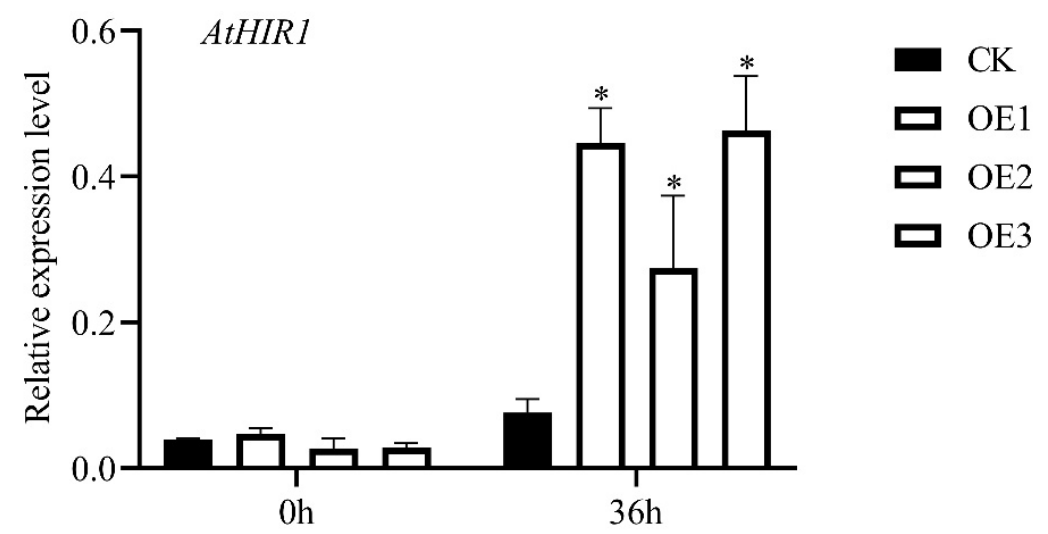

Figure 6. Relative expression of pathogen-related genes in the empty vector transgenic (CK) and

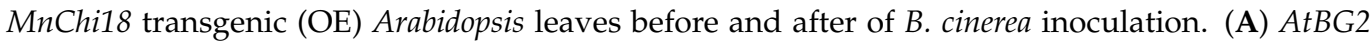
relative expression levels; (B) AtHIR1 relative expression levels. Error bars indicate the standard deviation, $n=3{ }^{*}{ }^{*}$-value $<0.05$.

\section{Discussion}

Chitinase genes are a large gene family, which play an important role in plant resistance. Clarifying the function of chitinase genes in plants is of great significance to plant-resistance breeding. So far, systematic genome-wide investigations of chitinase genes have been reported in many species. However, there is no systematic research report on mulberry chitinase genes. We identified a chitinase gene family in M. notabilis (Table 1 and Figure 1), for which a total of 26 mulberry chitinase genes were identified. Compared with the number of chitinase genes in other plants, mulberry is relatively small, but more than 
Arabidopsis [37]. This indicates that during the evolution process, the chitinase genes of mulberry have not been significantly amplified.

PR genes, including chitinase, are silenced or constitutively expressed at low levels in plants in the absence of pathogens, but are significantly induced in the presence of pathogens [38-40]. Consistent with previous reports, the expression of $\mathrm{MnChis}$ were both constitutive and inducible (Figure 2 and Table S2). The results showed that at least six $\mathrm{MnChi}$ genes can be induced after inoculation with B. cinerea. Class I (MnChi3), III (MnChi14) and IV (MnChi17/18) were significantly upregulated, Class II had no significantly induced expression, and Class V (MnChi20/23) was significantly down regulated. These findings indicate that the mulberry chitinase genes may have a different mechanism of action. Interestingly, the expression pattern of Class $\mathrm{V}$ was opposite to that of other plants [8,41], suggesting that the Class $\mathrm{V}$ chitinases in mulberry may have evolved different functions, which needs to be further studied.

To verify the function of the MnChi18 gene, we overexpressed this gene in Arabidopsis. Overexpressed MnChi18 plants were inoculated with B. cinerea, and ROS activity was detected by DAB and NBT staining (Figure 4). Compared with the empty vector plants, the plants overexpressing MnChil8 had less leaf damage and ROS accumulation, thus enhancing the resistance of Arabidopsis leaves to B. cinerea infection. Our results were consistent with previous studies that CaChilV1 gene interference in peppers significantly reduces its resistance [42]. MnChi18 may indirectly participate in the defense mechanism of transgenic plants by changing the transcription of other PR genes (Figure 6). Plant $\beta-1,3$-Glucanases (BG) are members of the PR2 family and one of the 17 PR protein families. It plays a key role in the response to biotic and abiotic stress. Overexpression of maize BG gene $Z m G n s$ in Arabidopsis can significantly increase the resistance to B. cinerea [43]. Arabidopsis hypersensitive-induced reaction (AtHIR) protein plays an important in plant innate immunity. Overexpression of AtHIR1 inhibited the growth of Pto DC3000 [44]. Overexpression of MnChi18 changes the expression of defense-related genes (BG2 and HIR1), which indicates that there is an interaction between them. Overexpression of the chitinase gene can usually increase the expression of the PR1 gene to enhance resistance [18,45], but overexpression of MnChi18 did not enhance the expression of AtPR1 (Figure S1), indicating that the mulberry chitin gene may have different mechanisms in plant resistance.

MDA is an important lipid peroxidation product involved in defense signal transduction in plants under biotic and abiotic stress [46]. However, our results suggested that overexpression of MnChi18 resulted in decreased MDA accumulation (Figure 5A). The MDA levels are usually associated with oxidative stress in plants. Therefore, overexpression of $\mathrm{MnChi18}$ gene avoids cell membrane damage. When plants are invaded by pathogenic microorganisms, it will cause the accumulation of ROS and the activation of plant defense enzymes, which help maintain cell integrity and eliminate peroxides [47]. After 36 hours of infection by B. cinerea, the CAT activity of $M n C h i 18$ transgenic Arabidopsis was significantly higher than that of the empty vector transgenic Arabidopsis (Figure 5B). This indicates that the overexpression of MnChi18 in Arabidopsis increases the ability to maintain cell integrity and thus resist $B$. cinerea infection.

\section{Conclusions}

This study identified three Class I, four Class II, seven Class III, four Class IV and eight Class $\mathrm{V}$ chitinase genes from the $M$. notabilis genome sequence. The ectopic expression of $\mathrm{MnChi18}$ in Arabidopsis increased its resistance to B. cinerea, and the disease symptoms were lighter. Overexpression of $\mathrm{MnChi18}$ protected plant cells from damage and enhanced the expression of plant resistance genes. This study will provide basic insights into the role of the $M n C h i 18$ gene in the resistance pathway.

Supplementary Materials: The following are available online at https://www.mdpi.com/article/10.3 390/genes13010098/s1: Figure S1: Relative expression of pathogen-related genes in empty vector transgenic (CK) and MnChi18 transgenic (OE) Arabidopsis leaves before and after of $\mathrm{B}$. cinerea 
inoculation; Table S1: Primers for real-time PCR; Table S2: Differential expression analysis of chitinase gene in Mock and Inoculated.

Author Contributions: Y.X. and X.J. conceived and designed the experiments; D.W. and S.H. performed the experiments; S.L., N.G. and Y.F. analyzed the data; Y.X. and D.W. wrote the manuscript. All authors have read and agreed to the published version of the manuscript.

Funding: This work was supported by the National Key R\&D Program of China (2018YFD1000602), National Natural Science Foundation of China (32171748; 32172799), Natural Science Foundation of Shandong Province (ZR2019MC017), and Modern Agricultural Technology System of Shandong Province (No. SDAIT-18-04).

Institutional Review Board Statement: Not applicable.

Informed Consent Statement: Not applicable.

Data Availability Statement: The datasets supporting the conclusions of this article are included within the article.

Acknowledgments: The authors thank the teachers and students in our research team for their help and support.

Conflicts of Interest: The authors declare no competing financial interest.

\section{References}

1. Nasser, W.; de Tapia, M.; Kauffmann, S.; Montasser-Kouhsari, S.; Burkard, G. Identification and characterization of maize pathogenesis-related proteins. Four maize PR proteins are chitinases. Plant Mol. Biol. 1988, 11, 529-538. [CrossRef]

2. Boller, T.; He, S.Y. Innate immunity in plants: An arms race between pattern recognition receptors in plants and effectors in microbial pathogens. Science 2009, 324, 742-744. [CrossRef] [PubMed]

3. Zipfel, C. Pattern-recognition receptors in plant innate immunity. Curr. Opin. Immunol. 2008, 20, 10-16. [CrossRef] [PubMed]

4. Tyler, L.; Bragg, J.N.; Wu, J.; Yang, X.; Tuskan, G.A.; Vogel, J.P. Annotation and comparative analysis of the glycoside hydrolase genes in Brachypodium distachyon. BMC Genom. 2010, 11, 600. [CrossRef] [PubMed]

5. Bravo, J.M.; Campo, S.; Murillo, I.; Coca, M.; San Segundo, B. Fungus- and wound-induced accumulation of mRNA containing a class II chitinase of the pathogenesis-related protein 4 (PR-4) family of maize. Plant Mol. Biol. 2003, 52, 745-759. [CrossRef] [PubMed]

6. Lu, H.C.; Lin, J.H.; Chua, A.C.; Chung, T.Y.; Tsai, I.C.; Tzen, J.T.; Chou, W.M. Cloning and expression of pathogenesis-related protein 4 from jelly fig (Ficus awkeotsang Makino) achenes associated with ribonuclease, chitinase and anti-fungal activities. Plant Physiol. Biochem. 2012, 56, 1-13. [CrossRef] [PubMed]

7. Mir, Z.A.; Ali, S.; Shivaraj, S.M.; Bhat, J.A.; Singh, A.; Yadav, P.; Rawat, S.; Paplao, P.K.; Grover, A. Genome-wide identification and characterization of Chitinase gene family in Brassica juncea and Camelina sativa in response to Alternaria brassicae. Genomics 2020, 112, 749-763. [CrossRef] [PubMed]

8. Chen, J.; Piao, Y.; Liu, Y.; Li, X.; Piao, Z. Genome-wide identification and expression analysis of chitinase gene family in Brassica rapa reveals its role in clubroot resistance. Plant Sci. 2018, 270, 257-267. [CrossRef] [PubMed]

9. Tobias, P.A.; Christie, N.; Naidoo, S.; Guest, D.I.; Kulheim, C. Identification of the Eucalyptus grandis chitinase gene family and expression characterization under different biotic stress challenges. Tree Physiol. 2017, 37, 565-582. [CrossRef] [PubMed]

10. Minic, Z. Physiological roles of plant glycoside hydrolases. Planta 2008, 227, 723-740. [CrossRef] [PubMed]

11. Sasaki, C.; Varum, K.M.; Itoh, Y.; Tamoi, M.; Fukamizo, T. Rice chitinases: Sugar recognition specificities of the individual subsites. Glycobiology 2006, 16, 1242-1250. [CrossRef] [PubMed]

12. Wang, S.; Shao, B.; Fu, H.; Rao, P. Isolation of a thermostable legume chitinase and study on the antifungal activity. Appl Microbiol. Biotechnol. 2009, 85, 313-321. [CrossRef] [PubMed]

13. Li, C.; Li, X.; Bai, C.; Zhang, Y.; Wang, Z. A chitinase with antifungal activity from naked oat (Avena chinensis) seeds. J. Food Biochem. 2019, 43, e12713. [CrossRef] [PubMed]

14. Liu, J.J.; Ekramoddoullah, A.K.; Zamani, A. A Class IV Chitinase Is Up-Regulated by Fungal Infection and Abiotic Stresses and Associated with Slow-Canker-Growth Resistance to Cronartium ribicola in Western White Pine (Pinus monticola). Phytopathology 2005, 95, 284-291. [CrossRef]

15. Maximova, S.N.; Marelli, J.P.; Young, A.; Pishak, S.; Verica, J.A.; Guiltinan, M.J. Over-expression of a cacao class I chitinase gene in Theobroma cacao L. enhances resistance against the pathogen, Colletotrichum gloeosporioides. Planta 2006, 224, 740-749. [CrossRef]

16. Dehestani, A.; Kazemitabar, K.; Ahmadian, G.; Jelodar, N.B.; Salmanian, A.H.; Seyedi, M.; Rahimian, H.; Ghasemi, S. Chitinolytic and antifungal activity of a Bacillus pumilus chitinase expressed in Arabidopsis. Biotechnol. Lett. 2010, 32, 539-546. [CrossRef]

17. Huang, Y.; Liu, H.; Jia, Z.; Fang, Q.; Luo, K. Combined expression of antimicrobial genes (Bbchit1 and LJAMP2) in transgenic poplar enhances resistance to fungal pathogens. Tree Physiol. 2012, 32, 1313-1320. [CrossRef] 
18. Dong, X.; Zhao, Y.; Ran, X.; Guo, L.; Zhao, D.G. Overexpression of a New Chitinase Gene EuCHIT2 Enhances Resistance to Erysiphe cichoracearum DC in Tobacco Plants. Int. J. Mol. Sci. 2017, 18, 2361. [CrossRef]

19. Nunez de Caceres Gonzalez, F.F.; Davey, M.R.; Cancho Sanchez, E.; Wilson, Z.A. Conferred resistance to Botrytis cinerea in Lilium by overexpression of the RCH10 chitinase gene. Plant. Cell Rep. 2015, 34, 1201-1209. [CrossRef]

20. Kasprzewska, A. Plant chitinases-Regulation and function. Cell Mol. Biol. Lett. 2003, 8, 809-824. [PubMed]

21. Huang, H.P.; Ou, T.T.; Wang, C.J. Mulberry (sang shen zi) and its bioactive compounds, the chemoprevention effects and molecular mechanisms in vitro and in vivo. J. Tradit. Complement. Med. 2013, 3, 7-15. [CrossRef]

22. Yuan, Q.; Zhao, L. The Mulberry (Morus alba L.) Fruit-A Review of Characteristic Components and Health Benefits. J. Agric. Food Chem. 2017, 65, 10383-10394. [CrossRef] [PubMed]

23. Chen, H.; Yu, W.; Chen, G.; Meng, S.; Xiang, Z.; He, N. Antinociceptive and Antibacterial Properties of Anthocyanins and Flavonols from Fruits of Black and Non-Black Mulberries. Molecules 2017, 23, 4. [CrossRef]

24. Jiang, Y.; Nie, W.J. Chemical properties in fruits of mulberry species from the Xinjiang province of China. Food Chem. 2015, 174, 460-466. [CrossRef]

25. Williamson, B.; Tudzynski, B.; Tudzynski, P.; van Kan, J.A. Botrytis cinerea: The cause of grey mould disease. Mol. Plant. Pathol. 2007, 8, 561-580. [CrossRef]

26. AbuQamar, S.F.; Moustafa, K.; Tran, L.S. 'Omics' and Plant Responses to Botrytis cinerea. Front. Plant Sci. 2016, 7, 1658. [CrossRef] [PubMed]

27. Dean, R.; Van Kan, J.A.; Pretorius, Z.A.; Hammond-Kosack, K.E.; Di Pietro, A.; Spanu, P.D.; Rudd, J.J.; Dickman, M.; Kahmann, R.; Ellis, J.; et al. The Top 10 fungal pathogens in molecular plant pathology. Mol. Plant. Pathol. 2012, 13, 414-430. [CrossRef] [PubMed]

28. Xin, Y.; Meng, S.; Ma, B.; He, W.; He, N. Mulberry genes MnANR and MnLAR confer transgenic plants with resistance to Botrytis cinerea. Plant Sci. 2020, 296, 110473. [CrossRef]

29. Xin, Y.; Ma, B.; Zeng, Q.; He, W.; Qin, M.; He, N. Dynamic changes in transposable element and gene methylation in mulberry (Morus notabilis) in response to Botrytis cinerea. Hortic. Res. 2021, 8, 154. [CrossRef]

30. He, N.; Zhang, C.; Qi, X.; Zhao, S.; Tao, Y.; Yang, G.; Lee, T.H.; Wang, X.; Cai, Q.; Li, D.; et al. Draft genome sequence of the mulberry tree Morus notabilis. Nat. Commun. 2013, 4, 2445. [CrossRef]

31. El-Gebali, S.; Mistry, J.; Bateman, A.; Eddy, S.R.; Luciani, A.; Potter, S.C.; Qureshi, M.; Richardson, L.J.; Salazar, G.A.; Smart, A.; et al. The Pfam protein families database in 2019. Nucleic Acids Res. 2019, 47, D427-D432. [CrossRef] [PubMed]

32. Eddy, S.R. Accelerated Profile HMM Searches. PLoS Comput. Biol. 2011, 7, e1002195. [CrossRef]

33. Tamura, K.; Stecher, G.; Peterson, D.; Filipski, A.; Kumar, S. MEGA6: Molecular Evolutionary Genetics Analysis version 6.0. Mol. Biol. Evol. 2013, 30, 2725-2729. [CrossRef] [PubMed]

34. Clough, S.J.; Bent, A.F. Floral dip: A simplified method for Agrobacterium-mediated transformation of Arabidopsis thaliana. Plant. J. 1998, 16, 735-743. [CrossRef]

35. Liu, H.; Ouyang, B.; Zhang, J.; Wang, T.; Li, H.; Zhang, Y.; Yu, C.; Ye, Z. Differential modulation of photosynthesis, signaling, and transcriptional regulation between tolerant and sensitive tomato genotypes under cold stress. PLoS ONE 2012, 7, e50785. [CrossRef] [PubMed]

36. Su, Y.; Xu, L.; Fu, Z.; Yang, Y.; Guo, J.; Wang, S.; Que, Y. ScChi, encoding an acidic class III chitinase of sugarcane, confers positive responses to biotic and abiotic stresses in sugarcane. Int. J. Mol. Sci. 2014, 15, 2738-2760. [CrossRef]

37. Cao, S.; Wang, Y.; Li, Z.; Shi, W.; Gao, F.; Zhou, Y.; Zhang, G.; Feng, J. Genome-Wide Identification and Expression Analyses of the Chitinases under Cold and Osmotic stress in Ammopiptanthus nanus. Genes 2019, 10, 472. [CrossRef] [PubMed]

38. $\mathrm{Wu}, \mathrm{C} . \mathrm{T}$; Bradford, K.J. Class I chitinase and $\beta-1,3$-glucanase are differentially regulated by wounding, methyl jasmonate, ethylene, and gibberellin in tomato seeds and leaves. Plant. Physiol. 2003, 133, 263-273. [CrossRef] [PubMed]

39. Datta, K.; Tu, J.; Oliva, N.; Ona, I.I.; Velazhahan, R.; Mew, T.W.; Muthukrishnan, S.; Datta, S.K. Enhanced resistance to sheath blight by constitutive expression of infection-related rice chitinase in transgenic elite indica rice cultivars. Plant Sci. 2001, 160, 405-414. [CrossRef]

40. Hamid, R.; Khan, M.A.; Ahmad, M.; Ahmad, M.M.; Abdin, M.Z.; Musarrat, J.; Javed, S. Chitinases: An update. J. Pharm. Bioallied Sci. 2013, 5, 21-29.

41. Bartholomew, E.S.; Black, K.; Feng, Z.; Liu, W.; Shan, N.; Zhang, X.; Wu, L.; Bailey, L.; Zhu, N.; Qi, C.; et al. Comprehensive Analysis of the Chitinase Gene Family in Cucumber (Cucumis sativus L.): From Gene Identification and Evolution to Expression in Response to Fusarium oxysporum. Int. J. Mol. Sci. 2019, 20, 5309. [CrossRef]

42. Ali, M.; Gai, W.X.; Khattak, A.M.; Khan, A.; Haq, S.U.; Ma, X.; Wei, A.M.; Muhammad, I.; Jan, I.; Gong, Z.H. Knockdown of the chitin-binding protein family gene CaChiIV1 increased sensitivity to Phytophthora capsici and drought stress in pepper plants. Mol. Genet. Genom. 2019, 294, 1311-1326. [CrossRef]

43. Xie, Y.R.; Raruang, Y.; Chen, Z.Y.; Brown, R.L.; Cleveland, T.E. ZmGns, a maize class I $\beta$-1,3-glucanase, is induced by biotic stresses and possesses strong antimicrobial activity. J. Integr. Plant. Biol. 2015, 57, 271-283. [CrossRef]

44. Qi, Y.; Tsuda, K.; Nguyen le, V.; Wang, X.; Lin, J.; Murphy, A.S.; Glazebrook, J.; Thordal-Christensen, H.; Katagiri, F. Physical association of Arabidopsis hypersensitive induced reaction proteins (HIRs) with the immune receptor RPS2. J. Biol. Chem. 2011, 286, 31297-31307. [CrossRef] 
45. Liu, Z.; Shi, L.; Yang, S.; Lin, Y.; Weng, Y.; Li, X.; Hussain, A.; Noman, A.; He, S. Functional and Promoter Analysis of ChiIV3, a Chitinase of Pepper Plant, in Response to Phytophthora capsici Infection. Int. J. Mol. Sci. 2017, 18, 1661. [CrossRef]

46. Gechev, T.; Gadjev, I.; Van Breusegem, F.; Inze, D.; Dukiandjiev, S.; Toneva, V.; Minkov, I. Hydrogen peroxide protects tobacco from oxidative stress by inducing a set of antioxidant enzymes. Cell. Mol. Life Sci. 2002, 59, 708-714. [CrossRef]

47. Klessig, D.F.; Durner, J.; Noad, R.; Navarre, D.A.; Wendehenne, D.; Kumar, D.; Zhou, J.M.; Shah, J.; Zhang, S.; Kachroo, P.; et al. Nitric oxide and salicylic acid signaling in plant defense. Proc. Natl. Acad. Sci. USA 2000, 97, 8849-8855. [CrossRef] 